\title{
Wandering Pneumonia Caused by Dabigatran
}

\author{
Masakazu Kono ${ }^{1}$, Kousuke Hirota ${ }^{2}$, Ayako Yokoe ${ }^{1}$, Chie Koumura ${ }^{1}$, \\ Toshihiko Sakai ${ }^{1}$ and Hirokazu Tojima ${ }^{1}$
}

\begin{abstract}
We herein describe the case of a 74-year-old man who experienced pulmonary consolidation and chest pain following administration of dabigatran, a novel oral anticoagulant. The consolidation settled spontaneously in another lung area, a condition sometimes referred to as "wandering pneumonia." Although we did not find specific pathological evidence of interstitial lung disease on transbronchial lung biopsy, a lung opacity spontaneously disappeared following discontinuance of dabigatran, and there was no recurrence. There are no other reports of dabigatran-induced lung injury, except alveolar hemorrhage and eosinophilic pneumonia. We should consider that any novel drug could cause various types of pulmonary injuries.
\end{abstract}

Key words: wandering pneumonia, organizing pneumonia, drug-induced lung injury, dabigatran

(Intern Med 53: 1825-1827, 2014)

(DOI: 10.2169/internalmedicine.53.2307)

\section{Introduction}

"Wandering pneumonia" (or migrating pneumonia) is the spontaneous migration of a pulmonary opacity that is detected radiographically. Organizing pneumonia (OP), including drug-induced lung injury (DLI), is one of the most frequent etiologies. We herein describe a case of migrating consolidation on chest X-ray following administration of the novel anticoagulant dabigatran. We describe this case because it is a unique pulmonary complication associated with dabigatran and the first report of dabigatran-associated lung injury other than alveolar hemorrhage and eosinophilic pneumonia.

\section{Case Report}

A 74-year-old male ex-smoker with a history of paroxysmal atrial fibrillation and a 6-month treatment history with dabigatran was referred to our hospital because of lung consolidation on chest X-ray, back pain, and exertional dyspnea. He had lung tuberculosis as a child. He reported no history of constitutional symptoms, such as anorexia, weight loss, or hemosputum. His respiratory system examination revealed no abnormal sounds.

A bronchoscopic examination had already been performed at another hospital, and no significant findings were revealed. Although his chest X-ray taken during the first medical examination revealed patchy opacities in the bilateral lungs (Fig. 1a), further patchy consolidations emerged in the right lower lung field and the area near the left hilus during a follow-up examination one month later (Fig. 2a). The chest high-resolution computed tomography (HRCT) scan performed during the first examination showed subpleural round consolidation that corresponded to his previous left back pain (Fig. 1b), but it had disappeared at the follow-up examination (Fig. 2b). His HRCT scan also revealed a novel consolidation surrounded by ground-glass attenuation, and some patchy opacities in the left middle lung field had improved (Fig. 1c, 2c). The series of radiographic findings could be referred to as "wandering pneumonia."

Blood tests revealed no anemia, eosinophilia, impaired renal function, or prolonged activated partial thromboplastin time (Table). We assayed the levels of autoantibodies for KL-6, surfactant protein D (SP-D), serum cryptococcal antigen, and beta-D-glucan and found that they were within the normal ranges. The patient never showed any evidence of eosinophilia throughout the follow-up.

Another bronchoscopy was performed to evaluate the non-resolving pneumonia on the third day after discontinuing dabigatran. Although bronchoalveolar lavage fluid (BALF) recovery was limited to $20 \%$, the recovered fluid

${ }^{1}$ Department of Pulmonary Medicine, Tokyo Rosai Hospital, Japan and ${ }^{2}$ Department of Pulmonary Medicine, Chiba University, Japan Received for publication December 13, 2013; Accepted for publication January 30, 2014 Correspondence to Dr. Masakazu Kono, kohno@tokyoh.rofuku.go.jp 

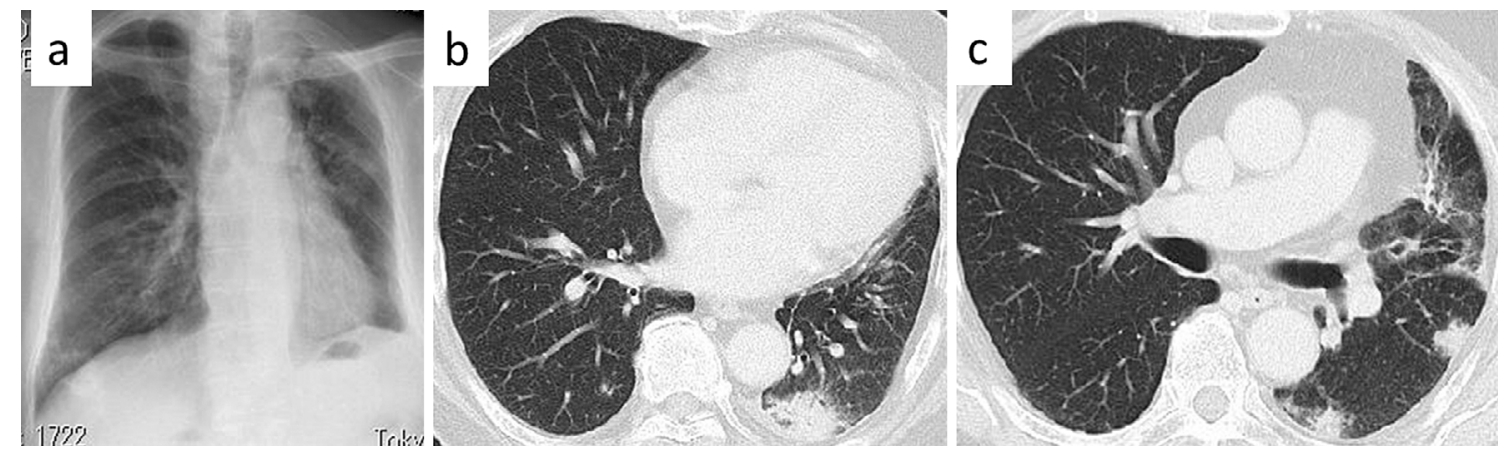

Figure 1. Chest X-ray and HRCT findings from the first medical examination. a) A chest X-ray demonstrated bilateral patchy opacity, primarily in the left middle right lower lung fields. b, c) An HRCT of the chest demonstrated patchy airspace consolidation, areas of ground-glass attenuation, and a few focal nodular areas of consolidation.
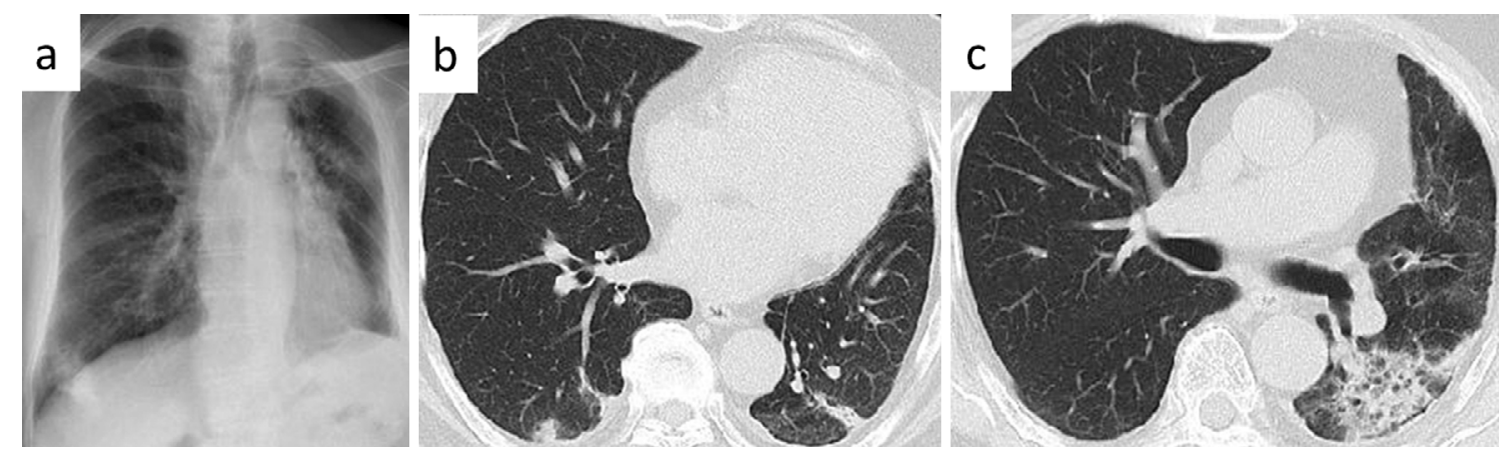

Figure 2. Follow-up chest X-ray and HRCT findings obtained 1 month later. a) A chest X-ray demonstrated an exacerbation of the pulmonary infiltrations in the right lower lung field and the area near the left hilus. b, c) HRCT demonstrated the emerging consolidation surrounded by ground-glass attenuation and some improving patchy opacities in the left middle lung field. An improvement of the previously existing opacities can be observed.

Table. Laboratory Findings on Admission

\begin{tabular}{|c|c|c|c|}
\hline \multicolumn{2}{|l|}{ Hematology } & \multicolumn{2}{|l|}{$\underline{\text { Serology }}$} \\
\hline White blood cell & $8,500 / \mu \mathrm{L}$ & $\overline{\mathrm{CRP}}$ & $1.1 \mathrm{mg} / \mathrm{dL}$ \\
\hline Neutrophil & $65.6 \%$ & $\mathrm{RF}$ & $\leq 3 \mathrm{IU} / \mathrm{mL}$ \\
\hline Lymphocyte & $26.8 \%$ & ANA & $\times 40$ \\
\hline Monocyte & $5.1 \%$ & MPO-ANCA & $\leq 10 \mathrm{EU}$ \\
\hline Eosinophil & $1.9 \%$ & PR3-ANCA & $\leq 10 \mathrm{EU}$ \\
\hline Basophil & $0.6 \%$ & KL-6 & $309 \mathrm{U} / \mathrm{mL}$ \\
\hline Hemoglobin & $13.8 \mathrm{~g} / \mathrm{dL}$ & SP-D & $54.0 \mathrm{ng} / \mathrm{mL}$ \\
\hline Platelet count & $24.0 \times 10^{3} / \mathrm{dL}$ & & \\
\hline & & $(1 \rightarrow 3)-\beta$-D-glucan & $\leq 5.0 \mathrm{pg} / \mathrm{mL}$ \\
\hline$\underline{\text { Biochemistry }}$ & & Cryptococcus antigen & negative \\
\hline $\mathrm{TP}$ & $7.6 \mathrm{~g} / \mathrm{dL}$ & & \\
\hline Alb & $4.0 \mathrm{~g} / \mathrm{dL}$ & $\underline{\text { Blood coagulation }}$ & \\
\hline T-bil & $0.3 \mathrm{mg} / \mathrm{dL}$ & PT-INR & 1.14 \\
\hline AST & $18 \mathrm{IU} / \mathrm{L}$ & APTT & 39.8 seconds \\
\hline ALT & $15 \mathrm{IU} / \mathrm{L}$ & & \\
\hline $\mathrm{LDH}$ & $182 \mathrm{IU} / \mathrm{L}$ & $\underline{\text { Urinalysis }}$ & \\
\hline ALP & $275 \mathrm{IU} / \mathrm{L}$ & Protein & $( \pm)$ \\
\hline BUN & $12 \mathrm{mg} / \mathrm{dL}$ & Glucose & $(-)$ \\
\hline CRE & $0.95 \mathrm{mg} / \mathrm{dL}$ & Occult Blood & $(-)$ \\
\hline $\mathrm{Na}$ & $139 \mathrm{mEq} / \mathrm{L}$ & & \\
\hline $\mathrm{K}$ & $3.8 \mathrm{mEq} / \mathrm{L}$ & & \\
\hline $\mathrm{Na}$ & $139 \mathrm{mEq} / \mathrm{L}$ & & \\
\hline $\mathrm{Cl}$ & $101 \mathrm{mEq} / \mathrm{L}$ & & \\
\hline Glu & $107 \mathrm{mg} / \mathrm{dL}$ & & \\
\hline
\end{tabular}

was not bloody. A cell fractionation of BALF revealed $12 \%$ neutrophils, $10 \%$ eosinophils, 23\% lymphocytes, and 63\% histiocytes. The patient's CD4/8 ratio of BALF lymphocytes was 0.63 . No significant pathological findings were observed in the transbronchial lung biopsy specimen. A microbiological examination of BALF revealed no evidence of infectious diseases, including acid-fast bacillus or fungus. The drug-induced lymphocyte stimulation test for dabigatran was negative.

We suspected that dabigatran had caused the lung opacity and instead administered warfarin, which was formerly prescribed to him. One month later, his symptoms, such as back pain and exertional dyspnea, had completely disappeared, as had the abnormal opacities on his chest X-ray. No recurrence had been observed for one year; therefore we diagnosed this patient's "wandering pneumonia" to be DLI caused by dabigatran.

\section{Discussion}

The patient presented with a case of "wandering pneumonia" that started following the administration of dabigatran. The pulmonary lesions completely disappeared after discon- 
tinuing dabigatran.

DLIs are diagnosed on the basis of clinical examination and radiographic and histological findings $(1,2)$. Although there is a long list of possible causes for multifocal consolidation on chest X-ray, the causes of migratory consolidation, (i.e., new areas of abnormalities appearing while other areas resolve, known as "wandering pneumonia") are relatively few. Cases that develop chronically as in the present case tend to be non-specific interstitial pneumonia or OP. According to the patient's unique radiographic course and his BALF results, his diagnosis corresponded with OP. Alveolar hemorrhage has been reported as a serious adverse effect of dabigatran, but the current patient had no corresponding symptoms or findings.

Dabigatran is a new anticoagulant agent from the direct thrombin inhibitor class. It is being studied for various clinical indications, and it is preferred to warfarin in some cases because it offers similar efficacy and does not require frequent blood tests for international normalized ratio monitoring (3). Since dabigatran was approved by the Ministry of Health, Labour and Welfare of Japan (MHLW) in 2010, its use is presumed to be increasing. Bleeding has been reported as an adverse event of dabigatran (1), and agencies concerned with medical drugs in several governments have been alerted to the risk. A few cases of alveolar hemorrhage $(4,5)$ and eosinophilic pneumonia (6) have been reported as adverse events associated with dabigatran use. However, there are no other reports of OP in the literature, especially in the manner of "wandering pneumonia." In September 2011, the MHLW issued an alert that dabigatran ad- ministration might be associated with interstitial lung disease in seven patients, including one who died one month after the onset of the interstitial lung injury, although an HRCT scan had revealed pre-existing interstitial lung opacities (7). It is therefore necessary to be aware of any potential adverse effects associated with novel drugs.

The authors state that they have no Conflict of Interest (COI).

\section{References}

1. Camus P. Drug induced infiltrative lung diseases. In: Interstitial Lung Disease. 4th ed. Schwarts MI, King TE Jr, Eds. BC Decker, Hamilton, 2003: 485-534.

2. Kubo K, Azuma A, Kanazawa M, et al. Consensus statement for the diagnosis and treatment of drug-induced lung injuries. Respir Investig 51: 260-277, 2013.

3. Connolly SJ, Ezekowitz MD, Yusuf S, et al. Dabigatran versus warfarin inpatients with atrial fibrillation. $N$ Engl J Med 361: 1139-1150, 2009.

4. Yokoi K, Isoda K, Kimura T, Adachi T. Diffuse alveolar hemorrhage associated with dabigatran. Intern Med 51: 2667-2668, 2012.

5. Husari A, Beydoun A, Sheik Ammar A, Makaron JE, Taher A. The untold story of Dabigatran etexilate: alveolar hemorrhage in an elderly patient with interstitial pulmonary fibrosis. J Thromb Thrombolysis 35: 81-82, 2013.

6. Fujita A, Inami N, Ashizawa $\mathrm{H}$, et al. Dabigatran etexilate-induced eosinophilic pneumonia. Nihon Kokyuki Gakkai Zasshi (Annals Jpn Respir Soc) 2: 414-418, 2013 (in Japanese).

7. Nippon Boehringer Ingelheim Co., Ltd. The announcement of revised package insert of Plazaxa capsules. http://www.bij-kusuri.jp/ information/attach/pdf/pxa_cap_info_201109.pdf (in Japanese).

(C) 2014 The Japanese Society of Internal Medicine http://www.naika.or.jp/imonline/index.html 